\title{
On the presence of the Amoimyrmex silvestrii (Emery, I 805) in Bolivia (Hymenoptera Formicidae)
}

\section{Antonio Scupola}

World Biodiversity Association c/o Museum of Natural History Verona, Lungadige Porta Vittoria 9, 37129 Verona, Italy; e-mail: scupolant@outlook.it

\begin{abstract}
The leaf-cutting species Amoimyrmex silvestrii (Myrmecinae Attini) here it is reported from the first time from Bolivia.

KEY WORDS Ants; Attini; Neotropical region; first record.

Received 16.01.2021; accepted 18.06.2021; published online 30.06.2021

\section{INTRODUCTION}

Recently, in the taxonomic work of Cristiano et al. (2020), three taxa of the leaf-cutting ant genus Acromyrmex Mayr 1865 are been transferred to the new genus Amoimyrmex Cristiano, Cardoso et Sandoval, 2020, based on molecular

and morphological investigations. The new genus includes Amoimyrmex striatus (Roger, 1863), A. silvestrii (Emery, 1905) and A. bruchi (Forel, 1912), all species having a smooth surface on the dorsum of the first tergite or weakly basally striated (while the surface is strongly tubercled in Acromyrmex).
\end{abstract}

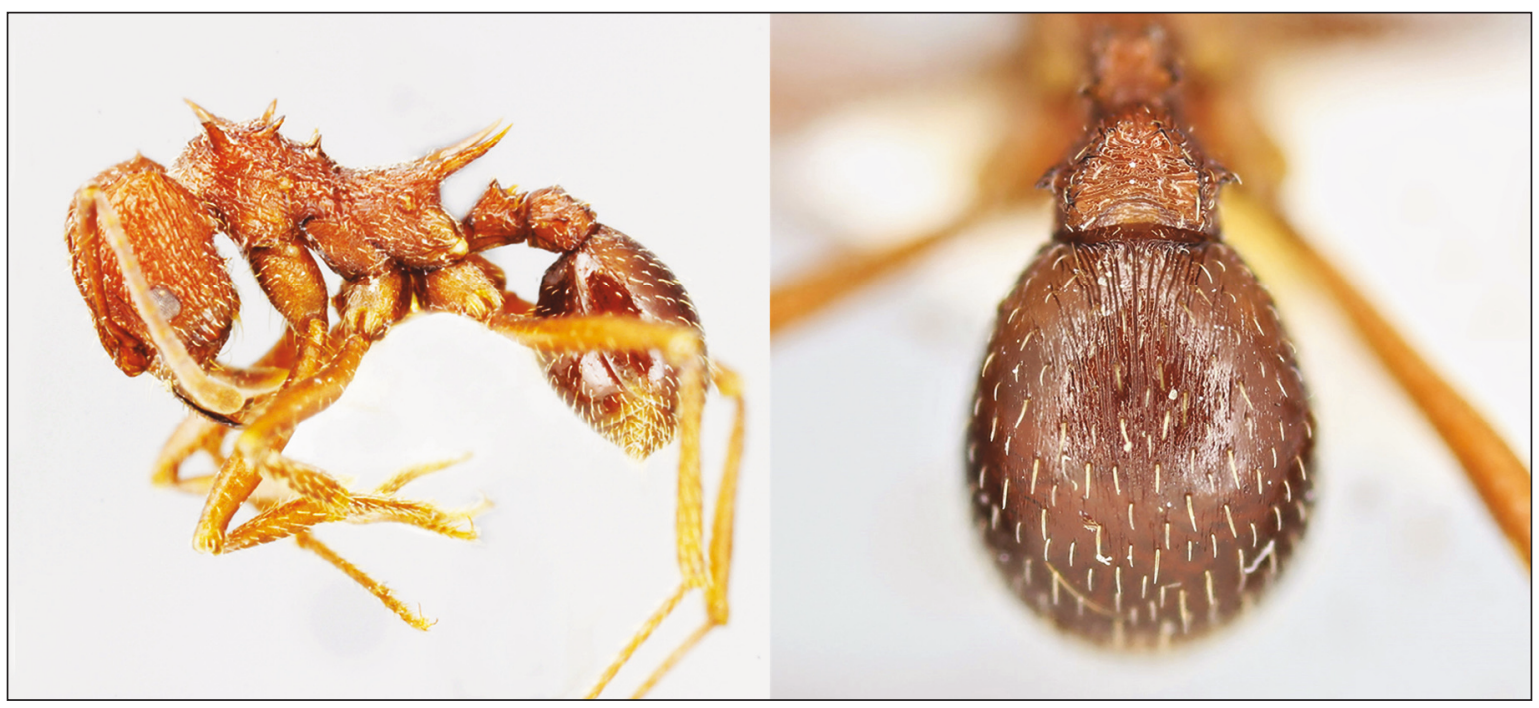

Figure 1. Amoimyrmex silvestrii worker: body (left), gaster in dorsal view (right). 
The distribution of this genus is restricted to southern part of South America, and in particular: Amoimyrmex bruchi reported from Argentina, but also known from one Bolivian locality (Chocabamba). Amoimyrmex striatus reported from southern Brazil, but known also from one locality in the western part of Argentina and two from Uruguay also. Amoimyrmex silvestrii reported also from Argentina and from Paraguay (one report).

Therefore, the reports of Amoimyrmex out of Argentina and Brazil are very scarce and new reports are always interesting to define the actual distribution of its species.

In this contest, I publish here a first report of Amoimyrmex silvestrii from Bolivia (Fig. 1) based on two workers collected in the East of the country: Bolivarian Chaco, Agua Caliente Santa Cruz, 9.VIII.2007 leg. Zorzin R. (pin code: \# 3189) (in the author's collection). In fact, this species was formerly lacking data from Bolivia, although, based on the distribution the presence in this country, had been speculated by Cristiano et al. (2020). Now, the presence is here confirmed.

In Bolivia, the other Amoimyrmex reported is $A$. bruchi, which differs from $A$. silvestrii by the different aspect of the dorsal surface of the first tergite: smooth in A. bruchi, well striated in A. silvestrii.

\section{REFERENCES}

Cristiano M.P. \& Cardoso D.C., Sandoval-Gomez V.E. \& Simões-Gomes F.C., 2020. Amoimyrmex Cristiano, Cardoso, Sandoval gen. nov. (Hymenoptera Formicidae) a new genus of leaf cutting ants revealed by multilocus molecular phylogenetic and morphological analysis. Austral Entomology, 59: 643-676. https://doi.org/10.1111/aen.12493 